\title{
Assessment of the Knowledge of the Adolescent Female Football Players Regarding the Carbohydrate and Its
} Importance

\author{
Shivani Sharma ${ }^{1}$, Ankita Sharma ${ }^{2}$ and G.Vani Bhushanam ${ }^{3}$ \\ 1. Department of Nutrition and Dietitics, Manav Rachna International University, Faridabad, Haryana 121004, India \\ 2. Department of Nutrition and Dietetics, Faculty of Applied Science, Manav Rachna International University, Faridabad, Haryana \\ 121004, India \\ 3. Department of Foods and Nutrition, Sports Science Centre, Sports Authority of India, New Delhi 110003, India
}

\begin{abstract}
Carbohydrate, in the form of glucose, is the preferred fuel for working muscles particularly during high intensity activity. Some carbohydrate will be used up irrespective of the type of exercise performed. A study was conducted to assess the knowledge of adolescent female football players regarding carbohydrate and its importance. It was found that $70 \%$ subjects were aware of the term carbohydrate. The awareness of the subjects regarding the term carbohydrate and its association with the function of carbohydrate is highly significant $(P<0.001)$. The awareness level of the subjects on carbohydrate sources, type of carbohydrate to be consumed before, after and during competition was not significant. A need for developing nutrition education tools and imparting nutrition education programs becomes pertinent to enable the players to choose appropriate diet to enhance their performance.
\end{abstract}

Key words: Carbohydrate, knowledge, nutrition education, performance.

\section{Introduction}

Sport is the form of physical activity that contributes to physical fitness, mental well-being and social interaction [1]. Involvement in sports is an integral part of development and teaches youth to lead active, healthy lives while developing many of the fundamental skills necessary for the youth to succeed. Sport significantly enhances the quality of life [2]. In recent years, sport and physical activity as a strategy for the empowerment of girls and women has been gaining recognition worldwide [3]. Increased participation of women in sports came with huge demands of specific needs of which nutritional needs plays an important role for optimal performance. Carbohydrate is one of the essential macronutrient required for the players. Carbohydrate is the primary and preferred fuel for working muscles. In the Indian

Corresponding author: Shivani Sharma, research field: sports nutrition. dietary regimen, about $65 \%$ to $80 \%$ energy is provided by carbohydrates. They are widely available and are an economic source of energy [4]. It is generally recommended that at least $55 \%$ of total calories of an athlete's diet should be from carbohydrate to store enough fuel for their events, especially for endurance competition. A minimal daily amount of carbohydrates recommended for an athlete is 300 grams if the total intake is $2000 \mathrm{kcal}$ [5]. Nutrition guidelines for the community express goals for carbohydrate intake in terms of the percentage of total energy they should provide. However, in situations where maximal glycogen storage is desirable or the athlete must meet the fuel bill of prolonged exercise sessions, carbohydrate needs are higher and more specific [6]. Carbohydrate is essential because they provide the glucose necessary to replace glycogen lost during training and competition. Carbohydrate consumption before and during exercise help in maintaining blood 
glucose levels and prevent premature fatigue [7]. Carbohydrate is a critical fuel source for the muscle and central nervous system. The availability of carbohydrate plays a key role in the performance of exercise lasting an hour or more. Therefore, sports nutrition guidelines promote carbohydrate intake before, during and after exercise to meet the fuel requirements of the activity [8]. The ability to sustain peak performance over an extended period of time is influenced by the availability of muscle glycogen. Carbohydrate loading is not recommended for short term competition since it can lead to a feeling of heaviness that is a disadvantage in high intensity competition [9]. Athletes may often rely on coaches for nutrition guidance in certain sports. Therefore, when coaches are misinformed about nutrition, this becomes a potential risk for athletes [10]. Nutrition training can be conveyed to the individuals through regular and wide educational programs as well as the individual training himself on his own settings [11].

\section{Materials and Methods}

The study was conducted in the sports academy of Faridabad. The sample consists of 50 female football players in the age group of 13 to 18 years. A pre-tested Questionnaire cum interview schedule was administered to collect data on general profile, physical activities, food habits, eating pattern and knowledge levels on carbohydrate and its importance.

\section{Statistical Analysis}

The data recorded for various characteristics were statistically analyzed. Mean, standard deviation and significant difference was calculated. Data coding and validations was also done. The collected data was analyzed by the distribution of the data according to the answers which was provided and chi square value was analyzed through associations between the knowledge related questions framed.

\section{Results and Discussion}

The assessments of the knowledge levels of female footballers reveal that $100 \%$ were aware about the term carbohydrate. Table 1 reveals that out of a total of 50 players, $74 \%$ were aware of the primary function that carbohydrate provides energy to the body and $26 \%$ were not aware of the function of the carbohydrate. And $6 \%$ of the payers were aware that proper carbohydrate intake helps in increasing performance.

Majority $(76 \%)$ of the subjects were aware that simple carbohydrate intake should be practiced during the competition, out of which, $60.5 \%$ were unaware of the reasons of the subjects while the rest were not aware of the use of simpler carbohydrate during the competition. None of the players were aware of Glycemic index of food and its relation to energy release.

Table 1 Knowledge level of female football players on carbohydrate.

\begin{tabular}{llll}
\hline S.N. & Variable & Number & Percent \\
\hline (i) & Function of carbohydrate & & 74 \\
& Energy provider & 37 & 6 \\
& Helps performance & 3 & 20 \\
(ii) & Don't know & 10 & 76 \\
& Carbohydrate consumption during competition & & 24 \\
Simple carbohydrate & Don't know & 38 & 0 \\
(iii) & Carbohydrate loading & 12 & 0 \\
(iv) & Glycemic index of food and its relation in energy release & 0 & 76 \\
(iv) & Food sources rich in carbohydrate & 0 & 70 \\
& Potato & & 58 \\
& Rice & 38 & 52 \\
& Bread & 35 & 14 \\
\hline
\end{tabular}


The carbohydrate rich sources the players could relate to are: Potato $(76 \%)$, Rice $(70 \%)$, Bread $(58 \%)$, Fruits (52\%) and Honey/Jam (44\%).

\section{Conclusion}

A need for developing nutrition education tools and imparting nutrition education programs becomes pertinent to enable the players to choose appropriate diet to enhance their performance.

\section{References}

[1] Tomson, L. M. 2001. "Childhood Depressive Symptoms, Physical Activity and Health Related Fitness." Journal of Sports \& Exercise Psychology 25 (4): 419.

[2] Harvey, J. 2002. "Feature Columnist-Sports and Recreation: Entertainment or Social Right?" Horizons 5 (1): 26-8.

[3] Brady, M. 2005. "Creating Safe Spaces and Building Social Assets for Young Women in the Developing World: A New Role for Sport." Women's Studies Quarterly 33 (1/2): 35-49.

[4] President's Council on Physical Fitness and Sports. 1997. "Physical Activity and Sport in the Lives of Girls." US Department of Health and Human Services, Washington,
DC.

[5] Sports Authority of India, National Institute of Nutrition. 2007. "Nutrition and Hydration Guidelines for Excellence in Athletic Performance." Assessed March, 2007. http://www.ilsiindia.org/PDF/Conf.\%20recommendations /Nutrition/Nutrition\%20\&\%20Hyd.\%20Guidelines\%20fo r\%20Athletes\%20Final\%20report.pdf

[6] Hawley, J., and Burke, L. 1998. Peak Performance: Training and Nutritional Strategies for Sport. Allen \& Unwin Academic.

[7] Foster-Powell, K., Holt, S. H. A., and Brand-Miller, J. C. 2002. "International Table of Glycemic Index and Glycemic Load Values.” American Journal of Clinical Nutrition 76: 5-56.

[8] Hawley, J., and Burke, L. 1998. "Eating for Recovery." In Peak Performance: Training and Nutritional Strategies for Sport. Sydney: Allen \& Unwin, 313-34.

[9] Srilakshmi, B. 2011. Dietetics, Sixth Edition, Chapter 23. Delhi: New Age International Publishers, 395-7.

[10] Cotugna, N., Vickery, C. E., and McBee, S. 2005. "Sports Nutrition for Young Athletes." The Journal of School Nursing 21 (6): 323-8.

[11] Rosenbloom, C. A., Jonnalagadda, S. S., and Skinner, R. 2002. "Nutrition Knowledge of Collegiate Athletes in a Division I National Collegiate Athletic Association Institution." Journal of the American Dietetic Association 102 (3): 418-20. 